\title{
Prevalence of Uremic Pruritus, Its Risk Factors and Impact on Health- Related Quality-Of-Life in Patients on Maintenance Hemodialysis
}

\author{
Simran Kaur ${ }^{1}$, Deepak Sharma², Suman Sethi', Preet Mohinder Singh Sohal ${ }^{1}$, Harmandeep Singh Chahal ${ }^{3}$, Vikas Makkar ${ }^{4}$ \\ ${ }^{1}$ Assistant Professor Nephrology, Dayanand Medical College and Hospital, Ludhiana, Punjab, India, ${ }^{2}$ Consultant Nephrologist, Sri Mata Vaishno Devi \\ Narayana Superspeciality Hospital, Katra, Jammu and Kashmir, India, ${ }^{3}$ Associate Professor Urology and Renal Transplant, Dayanand Medical College and \\ Hospital, Ludhiana, Punjab, India, ${ }^{4}$ Professor and Head Nephrology,Dayanand Medical College and Hospital, Ludhiana, Punjab, India.
}

\section{Abstract}

Background: Renal pruritus is one of the most debilitating symptom of chronic kidney disease especially affecting patients on maintenance hemodialysis. Subjects and Methods: It was a cross-sectional questionnaire based study. Demographic, dialysis related and biochemical parameters of maintenance hemodialysis patients were recorded, and a pre-defined questionnaire was put to them. Severity was calculated with 12 point pruritus severity scale (PSS), health-related quality of life with SKINDEX-10, and sleep survey with ITCH-MOS. Results: The total of 164 patients (mean age $52 \pm 17$ years, males-57.9\%, females-42.1\%) completing questionnaire and laboratory analysis were included in the study. Prevalence of pruritus was $53.7 \%$ (mild in $31.8 \%$, moderate- $45.5 \%$, severe- $22.7 \%$ ). Prevalence was higher in diabetic CKD $(\mathrm{p}=0.0001$ ), and irregularly dialyzed patients $(\mathrm{p}=0001)$. The severity of pruritus correlated with older age $(\mathrm{p}=0.004)$, shorter dialysis vintage $(\mathrm{p}=0.000)$, irregular dialysis (0.000), higher serum phosphorus (0.003), and parathyroid hormone level (0.000) and higher calcium-phosphorus product (0.001). SKINDEX-10 showed worsening symptoms, emotional and functional quality of life $(\mathrm{p}=0.000)$, and poorer sleep quality and quantity as per ITCH-MOS (0.000), with increasing severity of itching. Conclusion: Renal itch is highly prevalent in maintenance hemodialysis patients, most severely affecting diabetics, elderly, irregularly dialyzed patients, with poorly controlled mineral bone parameters. The severity correlates with worsening sleep and overall quality-of-life.

Keywords: Uremia, uremic/renal pruritus, maintenance hemodialysis, health-related quality of life, sleep.

Corresponding Author: Dr. Deepak Sharma, Consultant Nephrologist, Sri Mata Vaishno Devi Narayana Superspeciality Hospital, Katra, Jammu and Kashmir, India.

Received: December 2019

Accepted: December 2019

\section{Introduction}

Pruritus is one of the most bothersome symptom for chronic kidney disease (CKD), with reported prevalence as high as $50-90 \% .^{[1]}$ It affects patients in all stages of CKD, irrespective of underlying etiology, gender, age or comorbidities, however certain factors are hypothesized to affect its incidence and severity. Uremic pruritus significantly impairs the quality of life in CKD. The gravity of this seemingly trivial complaint can be judged from the fact that uremic pruritus has been an independent predictor of increased mortality, probably because its impact on the patient's quality of sleep..$^{[2-4]}$ Despite advances in the care of end-stage renal disease (ESRD) patients, the management of pruritus remains one of the most challenging clinical problems for the treating nephrologist. The present study intended to analyze the prevalence of uremic pruritus in maintenance hemodialysis patients, its relationship with demographic and metabolic parameters, and its impact on their health-related quality-of-life (HR-QOL) and sleep.

\section{Subjects and Methods}

This cross-sectional study was done in a large tertiary care centre in North India, in patients undergoing maintenance hemodialysis (with more than three months of dialysis vintage). The study was approved by the institutional ethical committee and a written informed consent was taken from each patient before inclusion in the study. The demographic details, etiology of CKD, hemodialysis vintage and frequency was recorded for all the patients. All the patients were being dialyzed on B-Braun-Dialog+ slow-flux hemodialysis machines, with formalin sterilized reused dialyzers. The laboratory parameters including hemoglobin, calcium, phosphorus, calcium-phosphorus product and parathyroid hormone levels were done in all the patients. The prevalence, intensity and diurnal variation of pruritus, its correlation with metabolic parameters, and its impact on the health related quality-of-life (HR-QOL) and sleep of the patients was analyzed on the basis of a pre-defined performa including 12 point pruritus severity scale (PSS) for severity, ${ }^{[5]}$ SKINDEX-10 for assessment of HR-QOL ${ }^{[6]}$ and sleep survey from the Medical Outcomes Study 
(MOS) ITCH-MOS for impact on sleep. ${ }^{[6]}$ Data were described in terms of frequencies (number of cases) and relative frequencies (percentages), mean \pm standard deviation $( \pm \mathrm{SD})$, as appropriate. Comparison of quantitative variables between the groups was done using ANOVA. For comparing categorical data, Chi square $(\chi 2)$ test was performed and exact test was used when the expected frequency was less than 5. A probability value (pvalue) less than 0.05 was considered statistically significant. All statistical calculations were done using SPSS (Statistical Package for the Social Science), SPSS-21 version statistical program for Microsoft Windows.

\section{Results}

The total of 183 patients were included in the study out of which 164 patients completing questionnaire and laboratory analysis were included in the final analysis. The mean age of the cohort was $52 \pm 17$ years, and it included 95 (57.9\%) males and 69 (42.1\%) females. Majority of the patient were in $5^{\text {th }}, 6^{\text {th }}$ and $7^{\text {th }}$ decades of life. The diabetic kidney disease $(n=70,42.7 \%)$ was the most common etiology for end stage kidney disease. Most of them (61\%) were undergoing twice a week hemodialysis. [Table-1].

\begin{tabular}{|c|c|c|}
\hline \multicolumn{3}{|c|}{$\begin{array}{l}\text { Table 1: Baseline characteristics of maintenance hemodialysis } \\
\text { patients in the study }\end{array}$} \\
\hline Baseline Characteristics & $\begin{array}{l}\text { Number Of Patients } \\
(\mathrm{N}=164)\end{array}$ & Percentage \\
\hline \multicolumn{3}{|l|}{ Gender distribution } \\
\hline Males & 95 & $57.90 \%$ \\
\hline Females & 69 & $42.10 \%$ \\
\hline \multicolumn{3}{|l|}{ Age distribution (in years) } \\
\hline$<20$ & 4 & $2.40 \%$ \\
\hline $21-30$ & 24 & $14.70 \%$ \\
\hline $31-40$ & 24 & $14.60 \%$ \\
\hline $41-50$ & 32 & $19.50 \%$ \\
\hline $51-60$ & 42 & $25.60 \%$ \\
\hline$>60$ & 38 & $23.20 \%$ \\
\hline \multicolumn{3}{|l|}{$\begin{array}{l}\text { Causes of Chronic kidney } \\
\text { disease }\end{array}$} \\
\hline Diabetic Nephropathy & 70 & $42.70 \%$ \\
\hline Hypertensive Nephrosclerosis & 38 & $23.20 \%$ \\
\hline Chronic glomerulonephritis & 30 & $18.30 \%$ \\
\hline Chronic interstitial nephritis & 17 & $10.40 \%$ \\
\hline Unexplained etiology & 9 & $5.40 \%$ \\
\hline \multicolumn{3}{|l|}{ Dialysis Vintage } \\
\hline Less than 1 year & 44 & $26.80 \%$ \\
\hline $1-3$ years & 76 & $46.40 \%$ \\
\hline $3-5$ years & 34 & $20.70 \%$ \\
\hline More than 5years & 10 & $6.10 \%$ \\
\hline \multicolumn{3}{|l|}{ Frequency Of Hemodialysis } \\
\hline Once In 10 Days & 16 & $9.80 \%$ \\
\hline Once Weekly & 34 & $20.70 \%$ \\
\hline Twice Weekly & 86 & $52.40 \%$ \\
\hline Thrice Weekly & 28 & $17.10 \%$ \\
\hline \multicolumn{3}{|l|}{ Miscellaneous } \\
\hline Smokers & 8 & $4.80 \%$ \\
\hline Active alcohol intake present & 14 & $8.50 \%$ \\
\hline Active opium addiction & 6 & $3.70 \%$ \\
\hline Hepatitis $\mathrm{C}$ positive & 8 & $4.80 \%$ \\
\hline Hepatitis B positive & 4 & $2.40 \%$ \\
\hline Retrovirus positive & 1 & $0.60 \%$ \\
\hline
\end{tabular}

Out of the total 164 patients, 88 patients $(53.7 \%)$ had pruritus, inspite of most of them being on anti-pruritic treatment. Pruritus affected 57.9\% males (55/95) and $47.8 \%$ $(33 / 69)$ females $(\mathrm{p}=0.202)$. Diabetics had higher prevalence of pruritus than non-diabetic CKD $(\mathrm{p}=0.0001)$. Higher prevalence was found in patients on irregular dialysis $(\mathrm{p}=0001)$. Active smokers, and alcohol and opium users and hepatitis B, C and retro positive patients were found to have high prevalence. Pruritus was divided into mild $(\mathrm{n}=28$, $31.8 \%)$, moderate $(n=40,45.5 \%)$ or severe $(n=20,22.7 \%)$ based on the 12-Item Pruritus Severity Scale (PSS).[Table2].

Table 2: Characteristics of patients with uremic pruritus in Maintenance Hemodialysis

\begin{tabular}{|c|c|c|}
\hline Parameters studied & $\begin{array}{l}\text { Number of patients } \\
\text { with problem/ total } \\
\text { number of patients }\end{array}$ & $\begin{array}{l}\text { Percentage of } \\
\text { patients }\end{array}$ \\
\hline $\begin{array}{l}\text { Prevalence of Uremic } \\
\text { Pruritus }\end{array}$ & $88 / 164$ & $53.70 \%$ \\
\hline \multicolumn{3}{|l|}{$\begin{array}{l}\text { Gender distribution of } \\
\text { uremic pruritus patients }\end{array}$} \\
\hline Males & $55 / 88$ & $62.50 \%$ \\
\hline Females & $33 / 88$ & $37.50 \%$ \\
\hline \multicolumn{3}{|l|}{ Anti-pruritic treatment } \\
\hline Presently on treatment & $65 / 88$ & $73.90 \%$ \\
\hline Past history of treatment & $77 / 88$ & $87.50 \%$ \\
\hline Compliance with treatment & $43 / 88$ & $48.90 \%$ \\
\hline Topical applications on skin & $77 / 88$ & $87.50 \%$ \\
\hline Oral anti-histaminics & $35 / 88$ & $39.8 \% \%$ \\
\hline Opioid analogues for pruritus & Nov-88 & $12.50 \%$ \\
\hline Gabapentin or pregabalin use & Jun-88 & $6.80 \%$ \\
\hline $\begin{array}{l}\text { Skin rash or itch marks } \\
\text { present }\end{array}$ & $69 / 88$ & $78.40 \%$ \\
\hline One area of body & $24 / 69$ & $34.80 \%$ \\
\hline Multiple areas of rash & $45 / 69$ & $65.20 \%$ \\
\hline Diurnal variation present & $49 / 88$ & $55.70 \%$ \\
\hline Nocturnal exacerbation & $44 / 49$ & $89.80 \%$ \\
\hline Day time exacerbation & May-49 & $10.20 \%$ \\
\hline $\begin{array}{l}\text { Correlation with dialysis } \\
\text { session }\end{array}$ & $32 / 88$ & $36.40 \%$ \\
\hline Increases during session & $30 / 32$ & $93.80 \%$ \\
\hline Decreases during session & 2 out of 32 & $6.20 \%$ \\
\hline \multicolumn{3}{|l|}{$\begin{array}{l}\text { Severity of pruritus (12-point } \\
\text { PSS)* }\end{array}$} \\
\hline Mild & $22 / 88$ & $25.00 \%$ \\
\hline Moderate & $41 / 88$ & $46.60 \%$ \\
\hline Severe & $25 / 88$ & $28.40 \%$ \\
\hline \multicolumn{3}{|l|}{$\begin{array}{l}\text { Etiology of CKD with } \\
\text { pruritus }\end{array}$} \\
\hline Diabetic CKD & $57 / 88$ & $64.80 \%$ \\
\hline Non-diabetic CKD & $31 / 88$ & $35.20 \%$ \\
\hline \multicolumn{3}{|l|}{ Frequency Of Hemodialysis } \\
\hline Once In 10 Days & $16 / 16$ & $100 \%$ \\
\hline Once Weekly & $34 / 34$ & $100 \%$ \\
\hline Twice Weekly & $28 / 86$ & $32.60 \%$ \\
\hline Thrice Weekly & $10.0 / 28$ & $35.70 \%$ \\
\hline \multicolumn{3}{|l|}{ Miscellaneous } \\
\hline Smoker & $05-08$ & $62.50 \%$ \\
\hline Alcohol intake & $01-05$ & $35.70 \%$ \\
\hline Opium addiction & 06-06 & $100 \%$ \\
\hline Hepatitis C positive & $04-08$ & $50 \%$ \\
\hline Hepatitis B positive & 03-04 & $75 \%$ \\
\hline Retrovirus positive & 01-01 & $100 \%$ \\
\hline
\end{tabular}

The severity of pruritus was correlated with various patient parameters (Table-3). Severity was higher in older hemodialysis patients $(\mathrm{p}=0.004)$, with shorter dialysis vintage $(\mathrm{p}=0.000)$, and irregular dialysis $(\mathrm{p}=0.000)$. Gender or diabetes did not affect the severity of pruritus. Among the 
metabolic parameters, pruritus significantly correlated with higher serum phosphorus $(\mathrm{p}=0.003)$, and parathyroid hormone $(\mathrm{p}=0.000)$ level. Most of the patient with severe pruritus had higher calcium-phosphorus product $(\mathrm{p}=0.001)$. Hemoglobin and calcium levels did not impact the severity.
SKINDEX-10 showed significantly worse health-related quality of life, with respect to symptoms, emotions and functionality in patients with severe pruritus $(\mathrm{p}=0.000)$. The ITCH-MOS score worsened significantly with severity of itching $(\mathrm{p}=0.000)$.

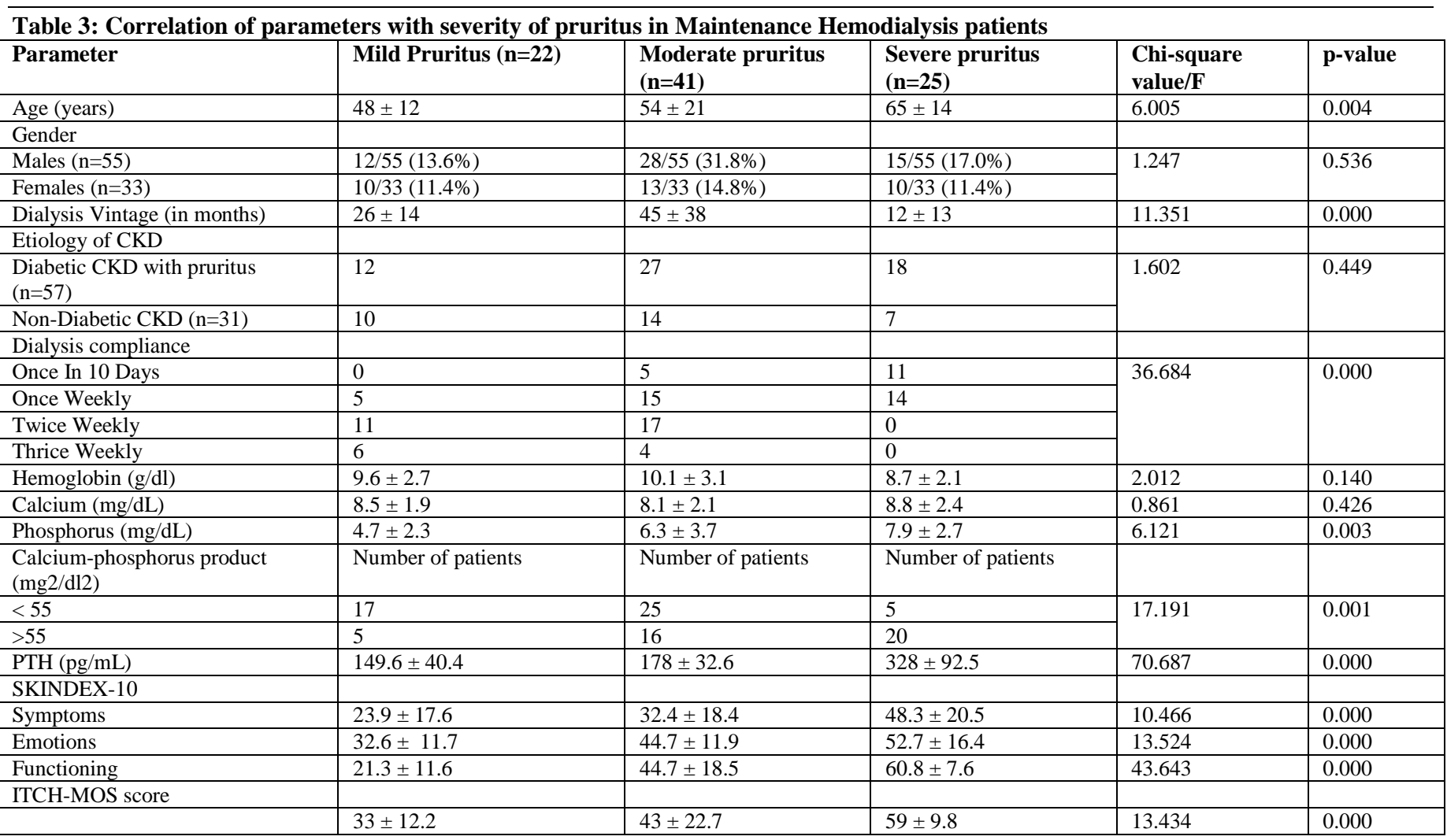

\section{Discussion}

The prevalence of uremic pruritus among patients undergoing hemodialysis is reported as $22-84 \%$, to as high as $90 \%$ in some older series. ${ }^{[2-4,7-10]}$ The itching may be mild to severe, continuous or episodic, localized or generalized, often with nocturnal exacerbation, ${ }^{[11]}$ and it affects patient's sleep and overall quality-of-life. The prevalence of sleep disturbances has been $9-76 \%$ in different series. ${ }^{[12]}$ Although the association of uremia with pruritus has been recognized for many years, the precise pathophysiologic mechanism remains obscure. It is possibly linked to inadequate removal of uremic toxins and abnormal calcium-phosphate metabolism in dialysis patients. Some other reasons being higher rate of xerosis, increased inflammatory cytokines and endogenous opioids. ${ }^{[2]}$ Several patient characteristics, biochemical and dialysis parameters have been reported by various investigators to affect uremic pruritus.

In this study we found the prevalence of uremic pruritus to be $53.7 \%$ in our maintenance hemodialysis patients, more in older age patients, with diabetic CKD, on irregular hemodialysis, and shorter dialysis vintage. No gender predisposition was found. The severity of pruritus correlated directly with increasing age, possibly due to age related dryness of skin exacerbating the condition. Patients on recently initiated dialysis therapy had tendency to avoid hemodialysis until severely symptomatic for azotemia. These irregularly dialyzed and shorter dialysis vintage patients had uncontrolled mineral bone parameters like higher phosphorus, parathyroid levels and calcium-phosphorus product and thus increased severity of pruritus. Hemoglobin and calcium did not correlate with severity of pruritus in our study.

Similar correlations with phosphorus levels, ${ }^{[13-15]}$ and older age, ${ }^{[13]}$ have been reported by other studies, but few other have also found higher serum calcium, male sex, low serum albumin level, current or recent smoking, dialysis adequacy, use of low-(versus high-) dialyzer, hepatitis C positivity and higher serum C-reactive protein levels to correlate with occurrence of pruritus. ${ }^{[13-17]}$

The SKINDEX-10 showed worsening symptom related, emotional, and functional quality of life parameters with increasing severity of pruritus. Similarly ITCH-MOS showed them to have poorer sleep quality and quantity, with worsening renal itch. Many other studies have reported presence of pruritus to correlate with decreased quality of life, and poor sleep with consequent depression, and an independent predictor of mortality, and other poor patient outcomes. ${ }^{[15,18,19]}$ However very few have systematically correlated the severity of pruritus with different parameters as our study. Lopes et $\mathrm{al}^{[20]}$ also reported patients with severe pruritus to have $25 \%$ decrease in kidney disease burdenrelated QoL and this decrease being primarily related to sleep disturbances, depressive symptoms, and dry skin. Mathur et $\mathrm{al}^{[6]}$ also found a statistically significant relationship between the intensity of pruritus and health-related QoL, particularly with regard to mood, social relations, and sleep. Similar such 
observations were seen in studies by Kosmadakis et al ${ }^{[21]}$ and Tessari et al ${ }^{[22]}$

Likes any other study, our study too had its limitations. It was a single centre, observational study. There could be innumerable other parameters which can influence pruritus, testing for all was not practically feasible. Therapeutic interventions were intentionally not taken into consideration, as compliance could not be ascertained, due to limited subjective benefits, and multi-therapy. A large multi-centric study in this regard can provide further insight in this regard.

\section{Conclusion}

Renal itch is one of the most debilitating symptom of patient on maintenance hemodialysis, affecting more than half of them. Old aged and irregularly dialyzed patients, with poorly controlled mineral bone parameters, are more severely affected. Measures for aggressive management of uremic pruritus can significantly improve their sleep parameters and overall quality-of-life.

\section{References}

1. Balaskas, EV, Chu M, Uldall RP, Gupta A, Oreopoulos DG. Pruritus in continuous ambulatory peritoneal dialysis and hemodialysis patients. Perit Dial Int. 1993; 13: S527-S532.

2. Berger TG, Steinhoff M. Pruritus and renal failure. Semin Cutan Med Surg. 2011; 30 (2): 99-100. doi:10.1016/j.sder.2011.04.005

3. Patel TS, Freedman BI, Yosipovitch G. An update on pruritus associated with CKD. Am J Kidney Dis. 2007; 50: 11-20.

4. Mettang M, Weisshaar E. Pruritus: Control of itch in patients undergoing dialysis. Skin Ther Lett. 2010; 15: 1-5.

5. Reich A, Bożek A, Janiszewska K, Szepietowski JC. 12-Item Pruritus Severity Scale: Development and Validation of New Itch Severity Questionnaire. BioMed Research International. 2017; Article ID 3896423: 7 pages. https://doi.org/10.1155/2017/3896423.

6. Mathur VS, Lindberg J, Germain M, Block G, Tumlin J, Smith M et al. A longitudinal study of uremic pruritus in hemodialysis patients. Clin J Am Soc Nephrol. 2010; 5: 1410-9.

7. Narita I, Iguchi S, Omori K, Gejyo F. Uremic pruritus in chronic hemodialysis patients. J. Nephrol. 2008;21: 161-5.

8. Kim KH, Lee MS, Choi SM, Ernst E. Acupuncture for treating uremic pruritus in patients with end-stage renal disease: a systematic review. J. Pain Symptom Manag. 2010; 40: 117-25. doi: 10.1016/j.jpainsymman.2009.11.325.
9. Khan TM, Wu DBC, Goh BH, Lee LH, Alhafez AA, Sulaiman SAS. An Observational Longitudinal Study Investigating the Effectiveness of $75 \mathrm{mg}$ Pregabalin Post-Hemodialysis among Uremic Pruritus Patients. Sci. Rep. 2016; 6: 36555. doi: 10.1038/srep36555.

10. Feramisco JD, Berger TG, Steinhoff M. Innovative management of pruritus. Dermatol Clin. 2010; 28: 467-78.

11. Sanai M, Aman S, Nadeem M, Kazmi AH. Dermatologic manifestations in patients of renal disease on hemodialysis. J. Pak. Assoc. Dermatol. 2016; 20: 163-8.

12. Rehman IU, Chohan TA, Bukhsh A, Khan TM. Impact of Pruritus on Sleep Quality of Hemodialysis Patients: A Systematic Review and Meta-Analysis. 2019. Medicina (Kaunas); 55(10): 699. doi: 10.3390/medicina55100699.

13. Pisoni RL, Wikstrom B, Elder SJ, Akizawa T, Asano Y, Keen ML, et al. Pruritus in haemodialysis patients: International results from the Dialysis Outcomes and Practice Patterns Study (DOPPS) Nephrol Dial Transplant. 2006; 21: 3495-505.

14. Duque MI, Thevarajah S, Chan YH, Tuttle AB, Freedman BI, Yosipovitch G. Uremic pruritus is associated with higher kt/V and serum calcium concentration. Clin Nephrol. 2006; 66: 184-91.

15. Narita I, Alchi B, Omori K, Sato F, Ajiro J, Sagaet D et al. Etiology and prognostic significance of severe uremic pruritus in chronic hemodialysis patients. Kidney Int. 2006; 69: 1626-32.

16. Ko MJ, Wu HY, Chen HY, Chiu YL, Hsu SP, Pai MF, et al. Uremic pruritus, dialysis adequacy, and metabolic profiles in hemodialysis patients: a prospective 5-year cohort study. PLoS One. 2013;8:e71404.

17. Chiu YL, Chen HY, Chuang YF, Hsu SP, Lai CF, Pai MF, et al. Association of uraemic pruritus with inflammation and hepatitis infection in haemodialysis patients. Nephrol Dial Transplant. 2008; 23: 3685-9.

18. Yamamoto Y, Hayashino Y, Yamazaki S, Akiba T. Depressive symptoms predict the future risk of severe pruritus in haemodialysis patients: Japan Dialysis Outcomes and Practice Patterns Study. Br J Dermatol. 2009;161: 384-9.

19. Combs SA, Teixeira JP, Germain MJ. Pruritus in Kidney Disease. Semin Nephrol. 2015; 35(4): 383-91. doi:10.1016/j.semnephrol.2015.06.009.

20. Lopes GB, Nogueira FC, de Souza MR, Penalva MA, de Amorim JL, Pisoni RL, et al. Assessment of the psychological burden associated with pruritus in hemodialysis patients using the kidney disease quality of life short form. Qual Life Res. 2012;21: 603-12.

21. Kosmadakis G, Papakonstantinou S, Theodoros C, Emmanouel P, Demetrios V, Nicolas Z. Characteristics of uremic pruritus in hemodialysis patients: data from a single center. Kidney Int. 2008; 74: $962-3$.

22. Tessari G, Dalle Vedove C, Loschiavo C, Tessitore N, Rugiu C, Lupo A, et al. The impact of pruritus on the quality of life of patients undergoing dialysis: a single centre cohort study. J Nephrol. 2009; 22: $241-8$.

Copyright: () the author(s), 2019. It is an open-access article distributed under the terms of the Creative Commons Attribution License (CC BY 4.0), which permits authors to retain ownership of the copyright for their content, and allow anyone to download, reuse, reprint, modify, distribute and/or copy the content as long as the original authors and source are cited.

How to cite this article: Kaur S, Sharma D, Sethi S, Sohal PMS, Chahal HS, Makkar V. Prevalence of Uremic Pruritus, Its Risk Factors and Impact on Health-Related Quality-Of-Life in Patients on Maintenance Hemodialysis. Acad. J Med. 2019;2(2):144-47.

DOI: dx.doi.org/10.21276/ajm.2019.2.2.37

Source of Support: Nil, Conflict of Interest: None declared. 